\title{
Thermodynamic Affinity of Elastomer-Solvent System and Barrier Properties of Elastomer Materials
}

\author{
S. KRZEMIŃSKA ${ }^{a * *}$ AND W.M. RZYMSKI ${ }^{b}$ \\ ${ }^{a}$ Central Institute for Labour Protection - National Research Institute (CIOP-PIB) \\ Department of Personal Equipment, Wierzbowa 48, 90-133 Łódź, Poland \\ ${ }^{b}$ Łódź University of Technology, Institute of Polymer and Dye Technology \\ B. Stefanowskiego 12/16, 90-924 Łódź, Poland \\ (Received November 6, 2012; in final form April 5, 2013)
}

\begin{abstract}
The aim of the study was to determine whether it is possible to correlate directly the barrier properties of elastomer materials assessed on the basis of the breakthrough time $t_{\mathrm{p}}$ with the thermodynamic affinity of the elastomer-solvent system, characterized by their solubility parameters $\delta$. According to EN ISO 6529:2001 standard, breakthrough time is defined as the time elapsing from the moment that the tested material sample gets in contact with the chemical to the moment in that a specified amount of the substance appears on the other side of the sample. Cured butyl rubber (IIR) in the form of flat membranes were tested in the study. For the nonpolar rubber-polar or rubber-nonpolar solvent systems it has been found that significant differences in rubber and solvent solubility parameters not in every case leads to better resistance to permeation. The properties of the permeating chemical and the rubber, including its polarity, shape, and molecule dimension of the solvent, are of considerable importance. A marked disparity of breakthrough times were observed for the permeation of polar or nonpolar solvents despite similar values of their solvent solubility parameter. The breakthrough time of the solvent from the homologous series (pentane, hexane and heptane) is determined not only by the rubber and solvent solubility parameters but by the size of the chemical molecule as well. Therefore, for the assessment of material barrier properties the thermodynamic affinity or dissimilarity of the elastomer and the permeating solvent is only semiquantitative in character.
\end{abstract}

DOI: $10.12693 /$ APhysPolA.124.146

PACS: 82.60.Lf, 61.25.hp, 64.75.Bc, 81.05.Lg

\section{Introduction}

The resistance of elastomer materials to permeation of chemical substances is tested in order to assess their potential applicability for production of special clothing and gloves protecting the human skin against exposure to hazardous chemical substances [1, 2]. The barrier properties of materials are determined on the basis of breakthrough time $t_{\mathrm{p}}$ for a particular substance, defined according to the EN ISO 6529:2001 standard as the time elapsing from the moment of contact of the tested material sample with the chemical to the moment that a specified amount of the tested substance appears on the other side of the sample.

The tests of this type are time-consuming and expensive $[3,4]$. Therefore, it has been attempted to develop new tools and methods facilitating the preliminary assessment of material resistance. Permeation involves transfer of chemical substances through barrier materials at the molecular level, and the gradient of substance concentration on both sides of the material is its driving force. In the discussed case, permeation is a non-equilibrium process, including sorption of the chemical by the material, its diffusion through the material, and

*corresponding author; e-mail: sykrz@ciop.lodz.pl desorption on the other side $[5,6]$. Thus, due to non-equilibrium swelling of the tested samples, the properties of the studied elastomer-solvent system undergo changes as a result of parallel processes of the solvent sorption and diffusion through the material. During determination of the breakthrough time (low concentration of the permeating solvent) the initial phase of the permeation process is taken into account, in which the solvent sorption and diffusion undergo continuous changes.

One of the methods allowing qualitative assessment of chemicals solubility levels in polymer-solvent systems utilizes the solubility parameters $\delta$ of the polymer and the substance, determining their thermodynamic affinity under equilibrium conditions. The solubility parameter is defined as the square root of molar cohesion energy, which is the energy necessary to overcome intermolecular interaction forces, per volume unit [7].

According to Hildebrand's theory of regular solutions [8-11], two substances characterized by similar solubility parameters should be soluble in each other. It is consistent with the general principles that chemical and structural similarity of the components favors their solubility. It is assumed that if the absolute difference of solubility parameters of the polymer $(\mathrm{p})$ and the substance $(\mathrm{s})$ is low $\left(\Delta \delta=\left|\delta_{\mathrm{p}}-\delta_{\mathrm{s}}\right|<1.0 \mathrm{MPa}^{0.5}\right)$ the polymer dissolves well in the solvent. As this difference increases, the solubility gradually goes down to the gradient threshold value $\left(\Delta \delta>2.4 \mathrm{MPa}^{0.5}\right)$, at which the solubility becomes negligible [12]. 
Hansen [9] extended the scope of application of the regular solutions theory to polar substances and proposed that besides dispersive interactions, also polar and hydrogen bond interactions should be considered.

During particular work-related activities, the workers are exposed to liquid chemicals. Therefore, it was considered expedient to undertake studies which might facilitate the preliminary selection of an appropriate protective material. Thermodynamic affinity, characterized by the difference of the polymer and chemical substance solubility parameters, may be a potentially useful measure.

\section{Materials}

The test objects were cured butyl rubber samples (IIR, BK 1675 N, manufacturer Togliattikauchuk Russia, density $0.9 \mathrm{~g} / \mathrm{cm}^{3}$ ) in the form of flat membranes. The rubber was conventionally cured with accelerator-oiled sulfur system ( 0.4 wt\% oil) added in $1.5 \mathrm{phr}+2 \mathrm{phr}$ accelerators (phr - parts per hundred rubber). The special butyl rubber was selected for the studies due to its properties and common use for coating fabrics designed for barrier clothing and gloves protecting against hazardous chemicals.

The rubber mixture was prepared according to the conventional method using a laboratory two-roll mill (rolls dimensions: $100 \times 200 \mathrm{~mm}^{2}$, roll temperature: $303-313 \mathrm{~K}$, roll velocity: $14-16 \mathrm{rpm})$. The mixture was then cured at $433 \mathrm{~K}$ for $25 \mathrm{~min}$, under the conditions determined on the basis of vulcametric tests according to PN ISO 3417:1994. The cured rubber samples were produced by press-molding.

\section{Chemical substances}

The following substances were selected for research concerning the effect of thermodynamic affinity of rubber-solvent system components on barrier properties of cured nonpolar butyl rubber:

- pentane, hexane, heptane as nonpolar aliphatic solvents belonging to a homologous series, characterized by solubility parameters similar to that of IIR,

- toluene - an aromatic hydrocarbon with the solubility parameter different from that of IIR,

- cyclohexane - a nonpolar cycloalkane with the solubility parameter similar to that of IIR,

- butyl acetate - a polar solvent with the intermediate difference of the solubility parameter comparing to that of IIR.

The selection of the solvents was also determined by their volatility under the test conditions, analytic potential of the apparatus used and their common presence at the worksites. Table I presents the values of the averaged solubility parameter $(\delta)$ of butyl rubber and the solvents
TABLE I

Values of averaged solubility parameter of butyl rubber $\delta_{k}\left[\mathrm{MPa}^{0.5}\right]$ and solvents selected for the tests $\delta_{r}\left[\mathrm{MPa}^{0.5}\right][7,13,14]$.

\begin{tabular}{c|c|c|c}
\hline \hline $\begin{array}{c}\text { Rubber, } \\
\text { solvent }\end{array}$ & $\delta_{k}, \delta_{r}$ & $\left|\delta_{k}-\delta_{r}\right|$ & $\left|\delta_{k}-\delta_{r}\right|^{2}$ \\
\hline IIR & 16.0 & - & - \\
pentane & 14.5 & 1.5 & 2.3 \\
hexane & 14.9 & 1.1 & 1.2 \\
heptane & 15.3 & 0.7 & 0.5 \\
cyclohexane & 16.8 & 0.8 & 0.6 \\
toluene & 18.2 & 2.2 & 4.8 \\
butyl acetate & 17.4 & 1.4 & 2.0
\end{tabular}

TABLE II

Values of polarity index $P[\mathrm{mN} / \mathrm{m}]$, dielectric constant $\varepsilon$ (at $298 \mathrm{~K}$ ) and dipole moment $M$ [D] for solvents used in tests.

\begin{tabular}{c|c|c|c}
\hline \hline Solvent & $P$ & $\varepsilon$ & $M$ \\
\hline pentane & 0.0 & 1.8 & 0.0 \\
hexane & 0.0 & 1,9 & 0.0 \\
heptane & 0.1 & 1.9 & 0.0 \\
cyclohexane & 0.0 & 2.0 & 0.0 \\
toluene & 2.3 & 2.4 & 0.4 \\
butyl acetate & 4.0 & 5.0 & 1.8
\end{tabular}

selected for the tests. We used solvents as pure or pure for analysis, produced by the Polish Chemical Reagents POCH S.A.). Table II presents the values of polarity index, dielectric constant and dipole moment which was used for classification of polarity solvent.

\section{Test method}

Cured rubber plates (diameter $40 \mathrm{~mm}$, thickness $0.35 \mathrm{~mm}$ ) were cut and placed in special two-chamber permeation cell, made of stainless steel. The design and dimensions of the permeation cell were consistent with the recommendations of the relevant standard - EN 6529:2001 - concerning testing the material resistance to permeation by liquid chemicals (Fig. 1). The sample was placed so that one its side faced towards the chamber filled with liquid chemical. The upper chamber of the cell was filled with a specified amount of the solvent $(10 \mathrm{ml})$. Through the lower chamber air stream was transferred with specific air flow intensity $(85 \mathrm{ml} / \mathrm{min})$, to collect the permeated solvent molecules and transport them to the analytic equipment - a gas chromatograph with a flame ionisation detector. The cell as well as the samples and chemical substances in glass flasks were preliminary thermostated for specific time (minimum $30 \mathrm{~min}$ ) at the same temperature as during the tests, i.e. $23 \pm 3{ }^{\circ} \mathrm{C}$.

After the end of thermostating, the software was turned on and recorded the time of tests and the concentration of permeated chemicals as peaks on the chromatograms. Every 1 min dosage valve automatically took 


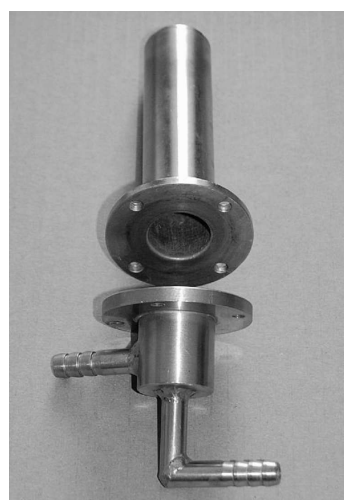

Fig. 1. Photograph of the permeation cell for testing resistance of polymer materials to permeation by chemical substances.

an equal amount of the air $(100 \mu \mathrm{l})$ flowing under the tested sample and directed it to the injection valve of the chromatograph. The experiment was conducted up to $6 \mathrm{~h}$.

Using the calibration curves and the chromatograms obtained, the concentration at which the threshold velocity of compound permeation through the material reached the given value $P=1 \mu \mathrm{g} /\left(\mathrm{cm}^{2} \mathrm{~min}\right)$, the breakthrough time $\left(t_{\mathrm{p}}\right)$ according to EN ISO 6529:2001 standard was determined or read directly from chromatograms. Small deviation of the tested sample thickness from the reference one $(0.35 \mathrm{~mm})$ was taken into consideration. The result of the breakthrough time experiment was expressed as an arithmetic average of three determinations, each from a different sample. The determined breakthrough times were subjected to statistical analysis to test the statistical significance of the differences found in relation to thermodynamic affinity defined by solubility parameters of systems: organic solvents - cured rubber. For statistical conclusion, Excel-based analysis of variance (ANOVA) was used, with the adopted significance level of $P=0.05$.

\section{Results and discussion}

The results of determined breakthrough times are presented in Table III and correlated both with the absolute difference of averaged rubber and solvent solubility parameters $\left|\delta_{k}-\delta_{r}\right|$ and with its square $\left|\delta_{k}-\delta_{r}\right|^{2}$, Figs. 2, 3 .

As it follows from the analysis of test results, there are no direct correlations of the breakthrough time either with the difference between rubber and solvent solubility parameters $\left|\delta_{k}-\delta_{r}\right|$, or with the squared value of this difference $\left|\delta_{k}-\delta_{r}\right|^{2}$, Figs. 2, 3 .

The determined breakthrough time for some of the tested solvents with similar chemical structures, belonging to a homologous series (pentane, hexane and heptane) and the difference of rubber and solvent solubility parameters $\left|\delta_{k}-\delta_{r}\right|$, indicates a considerable effect of the molecule size of the permeating substance. The

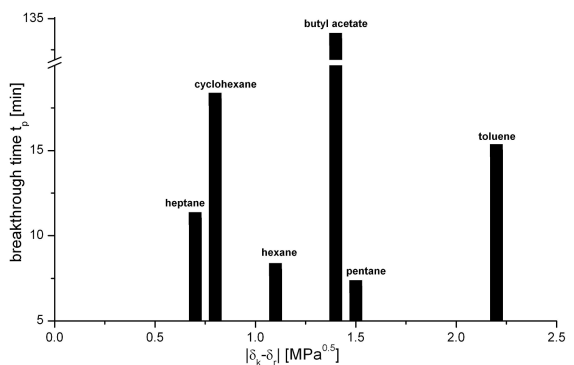

Fig. 2. Breakthrough time $t_{\mathrm{p}}[\mathrm{min}]$ of the tested solvents through cured IIR versus the absolute difference of rubber and solvent solubility parameters $\left|\delta_{k}-\delta_{r}\right|$ $\left[\mathrm{MPa}^{0.5}\right]$.

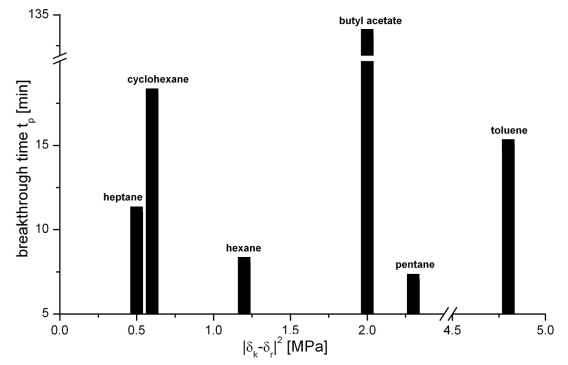

Fig. 3. Breakthrough time $t_{\mathrm{p}}$ [min] of the tested solvents through cured IIR versus squared absolute difference of rubber and solvent solubility parameters $\left|\delta_{k}-\delta_{r}\right|^{2}[\mathrm{MPa}]$.

breakthrough time increases in proportion to the chain length of the solvent molecule. Although an increase in breakthrough time due to decrease in the difference between rubber and solvent solubility parameters $\left|\delta_{k}-\delta_{r}\right|$ was noted, the difference in the determined breakthrough time for pentane and hexane did not reach statistical significance $\left(t_{\mathrm{p} \text { pentane }}=7 \mathrm{~min}, t_{\mathrm{p} \text { hexane }}=8 \mathrm{~min}\right.$, $P=0.14946)$; therefore, these results indicate a trend only. It should be underlined that the values of equilibrium swelling of cured IIR in these solvents correlate well with their thermodynamic similarity with rubber $\left(Q_{\mathrm{v} \text { pentane }}=1.56 \mathrm{ml} / \mathrm{ml}, Q_{\mathrm{v} \text { hexane }}=2.03 \mathrm{ml} / \mathrm{ml}\right.$, $Q_{\mathrm{v} \text { heptane }}=2.32 \mathrm{ml} / \mathrm{ml}$ ).

TABLE III

Determined breakthrough time $t_{\mathrm{p}}[\mathrm{min}]$ of solvents through cured butyl rubber, and values of absolute difference of rubber and solvent solubility parameters $\left|\delta_{k}-\delta_{r}\right|\left[\mathrm{MPa}^{0.5}\right]$.

\begin{tabular}{c|c|c}
\hline \hline Rubber/solvent & $\left|\delta_{k}-\delta_{r}\right|$ & $t_{\mathrm{p}}$ \\
\hline butyl rubber/pentane & 1.5 & $7 \pm 2$ \\
butyl rubber/hexane & 1.1 & $8 \pm 1$ \\
butyl rubber/heptane & 0.7 & $11 \pm 1$ \\
butyl rubber/toluene & 2.2 & $15 \pm 0$ \\
butyl rubber/cyclohexane & 0.8 & $18 \pm 1$ \\
butyl rubber/butyl acetate & 1.4 & $130 \pm 10$
\end{tabular}


In the case of IIR-heptane system, the difference between solubility parameters $\left|\delta_{k}-\delta_{r}\right|=0.7 \mathrm{MPa}^{0.5}$, and breakthrough time $t_{\mathrm{p}}=11 \mathrm{~min}$, whereas for IIRpentane system, the difference of solubility parameters $\left|\delta_{k}-\delta_{r}\right|=1.5 \mathrm{MPa}^{0.5}$ was almost doubled, but the breakthrough time was the shortest, $t_{\mathrm{p}}=7 \mathrm{~min}$ only. Therefore, for the nonpolar rubber-nonpolar solvent systems, characterized by a low difference of rubber and solvent solubility parameters very short breakthrough times can be expected and vice versa, a considerable difference between the solubility parameters within the system should favor longer breakthrough times. However, the above presented results and the tests of the cured butyl rubber-toluene system $\left(\left|\delta_{k}-\delta_{r}\right|=2.2 \mathrm{MPa}^{0.5}\right)$, characterized by the most significant difference in the solubility parameters, confirm this conclusion only quantitatively. The sample breakthrough time determined for that solvent is slightly longer (15 min) than that determined for aliphatic solvents (pentane, hexane, heptane), for which the differences in solubility parameters were much smaller (from 0.5 to $1.5 \mathrm{MPa}^{0.5}$ ). An opposite situation was noted in the case of polar butyl acetate permeation, characterized, in comparison with above mentioned solvents, by an intermediate difference of solubility parameters $\left(\left|\delta_{k}-\delta_{r}\right|=1.4 \mathrm{MPa}^{0.5}\right)$, for which the rather long and longest breakthrough time was determined $\left(t_{\mathrm{p} \text { butyl acetate }}=130 \mathrm{~min}\right)$.

The analysis of permeation tests with solvents containing the same number of carbon atoms in the molecule but different chemical structure and shape indicates that although IIR-hexane and IIR-cyclohexane systems are characterized by similar solubility parameter gradients $\left|\delta_{k}-\delta_{r}\right|$ (IIR-hexane $1.1 \mathrm{MPa}^{0.5}$; IIR-cyclohexane $\left.0.8 \mathrm{MPa}^{0.5}\right)$, the difference between their breakthrough times was over twofold (hexane $8 \mathrm{~min}$; cyclohexane $18 \mathrm{~min})$. On the other hand, IIR-heptane $\left(\mathrm{C}_{7} \mathrm{H}_{16}\right)$ and IIR-toluene $\left(\mathrm{C}_{7} \mathrm{H}_{8}\right)$ systems with considerably different parameter gradients $\left|\delta_{k}-\delta_{r}\right|$ (IIR-heptane $0.7 \mathrm{MPa}^{0.5}$; IIR-toluene $\left.2.2 \mathrm{MPa}^{0.5}\right)$, are characterized by similar but statistically different $(P=0.00004)$ values of breakthrough time $\left(t_{\mathrm{p} \text { heptane }}=11 \mathrm{~min} ; t_{\mathrm{p} \text { toluene }}=15 \mathrm{~min}\right)$. The above indicates that the molecule shape affects significantly the solvent permeation velocity through cured IIR.

The analysis of the results also included an effort to find a correlation between parameters characterizing the polarity of solvent: dipole moment, dielectric constant, polarity index (see Table II) and breakthrough time specifying barrier properties of the material. In the case of non-polar solvents with both - the dipole moment and polarity index were 0 , the experimentally determined breakthrough time of nonpolar butyl rubber vulcanizates was short and did not exceed 20 min. In contrast, permeation of butyl acetate, characterizing by high dipole moment (1.8 D) and polarity index (4.0), occurring at a slower rate and breakthrough time was significantly higher than for other solvents $\left(t_{\mathrm{p}}\right.$ butyl acetate $\left.=130 \mathrm{~min}\right)$. To the same conclusions there reached authors consid- ering next parameter - dielectric constant, which was similar and ranged from 1.8 to 2.4 for five from six solvents, characterizing by short breakthrough time through material, Fig. 4. The results obtained during the analysis of the parameters characterizing the polarity of solvents are qualitatively compatible with the proposals concerning solubility parameters.

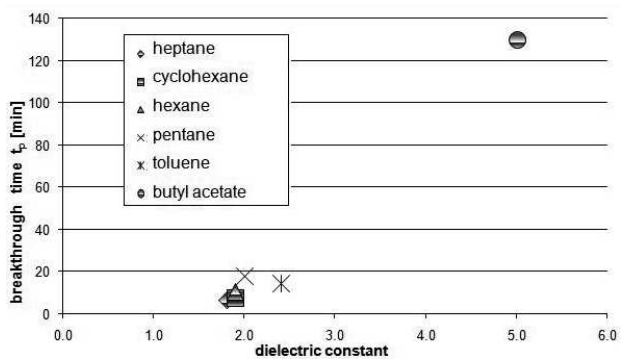

Fig. 4. Breakthrough time $t_{\mathrm{p}}[\mathrm{min}]$ of the tested solvents through cured IIR versus dielectric constant of solvents.

The results of our research are qualitatively consistent with previous literature reports $[8,15]$ provided that thermodynamic affinity can be used for a prediction of the breakthrough time for the elastomer-solvent system only for substances with similar chemical structure. Studies by Lara et al. [8] concerning permeation of dichloromethane and tetrachloroethylene through glove samples made of chloroprene rubber (CR) confirmed that polymer materials with solubility parameters similar to solubility parameters of solvents $\left(\mathrm{CR}-18.5 \mathrm{MPa}^{0.5}\right.$, dichloromethane - $19.8 \mathrm{MPa}^{0.5}$, tetrachloroethylene 19.0 $\mathrm{MPa}^{0.5}$ ) are the least resistant to exposure to these solvents. Contrary to expectations, cured CR was not resistant to permeation by nitrobenzene possessing a significantly higher solubility parameter $\left(20.5 \mathrm{MPa}^{0.5}\right)$ than that of CR.

Our results are consistent with the findings of Chao et al. [15] in their study concerning permeation of solvents through polymer membranes and confirm that values of the solubility parameters can be helpful in prediction of resistance to solvents in the case of some polymer-solvent systems only. Although a study concerning permeation of toluene, benzene, ethylbenzene and $p$-xylene through chloroprene and acrylonitrile rubber demonstrated that the permeation coefficient for the solvent, associated with diffusion of the substance molecules, was in inverse proportion to the difference between rubber and solvent solubility parameters $\left(R^{2}=0.841\right.$ for acrylonitrile rubber and $R^{2}=0.976$ for chloroprene rubber). However, these conclusion was not confirmed in the studies of other polymer-solvent systems.

\section{Conclusions}

From presented research it follows that prediction of barrier properties of elastomer-solvent systems based on 
thermodynamic affinity of the elastomer and the solvent can be only qualitative in character. The polarity of the rubber and the tested solvents is of considerable importance here. A marked differentiation of breakthrough times through nonpolar butyl rubber were observed for the permeating polar or nonpolar solvents despite similar values of their difference of solubility parameters.

In the case of nonpolar solvents, characterized by low difference of solubility parameter in comparison to nonpolar IIR, short breakthrough times were observed, and it seems that the shape and size of the permeating molecule are the factors determining the permeation velocity. Permeation of a polar solvent (butyl acetate) with intermediate thermodynamic affinity to IIR is characterized by breakthrough time exceeding several times the values determined for nonpolar solvents with similar solubility parameter values.

\section{Acknowledgments}

The publication has been based on the results of Phase I of the National Programme "Safety and working conditions improvement" and statutory activity, funded in the years 2008-2010 in the area of scientific research and development works by the Ministry of Science and Higher Education/The National Centre for Research and Development. The Programme coordinator: Central Institute for Labour Protection - National Research Institute.

\section{References}

[1] S. Krzemińska, W.M. Rzymski, Int. J. Occup. Safety Ergonom. JOSE 17, 41 (2011).

[2] S. Krzemińska, W.M. Rzymski, Mater. Sci. Poland 29, 285 (2012).

[3] S. Krzemińska, W.M. Rzymski, J. Phys., Conf. Ser. 146, 012007 (2009).

[4] S. Krzemińska, W.M. Rzymski, Polimery 57, 551 (2012) (in Polish).

[5] N. Vahdat, V.D. Sullivan, J. Appl. Polym. Sci. 79, 1265 (2001).

[6] R. Forte, J.L. Leblanc, J. Appl. Polym. Sci. 45, 1473 (1992).

[7] A.F.M. Barton, Chem. Rev. 75, 751 (1975).

[8] J. Lara, B. Roberge, A. Velazquez, H. Nelisse, Report IRSST, Montreal 1991.

[9] C.M. Hansen, Prog. Org. Coat. 51, 55 (2004).

[10] S. Połowiński, Physical chemistry of polymers, Technical University, Łódź 2001 (in Polish).

[11] J. Olsson, J. Membr. Sci. 186, 239 (2001).

[12] L. Huppenthal, Polymer Solutions, Scientific Publisher, Toruń 2008.

[13] C.J. Sheehan, C.J. Bisio, Rubb. Chem. Techn. 39, 149 (1966).

[14] A.F.M. Barton, CRC Handbook of Solubility Parameters and Other Cohesion Parameters, CRC Press Inc., Boca Raton, Florida 1983.

[15] K.P. Chao, J.S. Lai, H.C. Lin, Y.P. Hsu, Polym. Test. 25, 975 (2006). 